\title{
OS NOVOS DIREITOS DOS EMPREGADOS DOMÉSTICOS TRAZIDOS PELA EMENDA CONSTITUCIONAL 72/2013
}

\author{
Yvens Dixon Moreira Aragão de Lima \\ Aluno do Curso de Direito da FA7. \\ Artigo orientado pelo prof. Ms. Paulo Rogério Marques \\ de Carvalho (FA7) \\ yvensdixon@hotmail.com
}

Sumário: Introdução. 1. A evolução que culminou com a promulgação da Emenda Constitucional 72. 2. Os novos direitos dos empregados domésticos. 3. Resultados. Considerações finais.

Resumo: A Emenda Constitucional 72 (EC 72) promulgada no dia 3 de abril de 2013 ampliou para os empregados domésticos vários direitos. A nova lei, acrescida ao texto constitucional, representa um enorme avanço para todos os domésticos, pois os igualou em direitos aos demais empregados regidos pela Consolidação das Leis do Trabalho (CLT). Serão apresentados os direitos garantidos aos empregados domésticos pela Emenda, com sua distinção quanto à eficácia. Por fim, são expostas algumas consequências já observadas após a publicação da Emenda.

Palavras-chave: Emenda Constitucional 72. Empregados domésticos. Novos direitos.

\section{INTRODUÇÃO}

O trabalhado doméstico sempre foi diferenciado do trabalho normal, diferença essa reforçada pelo desequilíbrio de direitos assegurados aos trabalhadores de cada categoria.

Assim, somente no século XXI foi extirpado de vez o desequilíbrio de direitos contra os empregados domésticos, o qual os renegava a um patamar inferior de trabalhadores, sendo estes desprestigiados de direitos há tantos anos garantidos aos demais trabalhadores celetistas.

A Emenda Constitucional 72, denominada popularmente de Emenda das Domésticas, é muito abrangente, uma vez que criou vários direitos, entretanto foi muito omissiva ao não trazer em seu bojo a solução para problemáticas advindas com a nova lei, como: a cargo de quem ficarão as despesas advindas com os novos direitos ou como serão regulados os direitos de eficácia limitada.

OBJETIVOS: Pesquisar, debater e criticar sobre a regulamentação e efetivação dos novos direitos garantidos aos empregados domésticos pela Emenda Constitucional 72. Além disso, apresentar as primeiras consequências dos novos direitos na realidade prática.

METODOLOGIA: Este artigo busca responder quais as consequências advindas com a promulgação da Emenda Constitucional 72. Para isso, é utilizada basicamente a pesquisa doutrinária, porém também são pesquisados artigos acadêmicos e notícias relacionadas ao tema, além de ser coletada algumas legislações, sendo em seguida pormenorizadas. 


\section{A Evolução que Culminou com a Promulgação da Emenda Constitucional 72}

A abolição da escravidão, em 1888, não foi acompanhada de nenhuma política de inclusão na sociedade para os escravos libertos. Assim, a grande maioria, sem ter para onde ir, nem possuir qualificação e marcada pelo estigma escravagista da época, acabava permanecendo com seus antigos senhorios, recebendo apenas comida e moradia como pagamento.

Os "novos" trabalhadores domésticos brasileiros eram em quase sua totalidade os antigos escravos que sem alternativa melhor permaneciam com os antigos donos. Os outrora senhorios de escravos passaram a ser encarados como benfeitores por assistirem a tantos ex-escravos, agora, na condição de empregados, porém possuíam os mesmos custos, alimentação e moradia.

Casagrande discorre sobre a inferiorização dada aos domésticos:

Muitos dos escravos domésticos, após a abolição, permaneceram na mesma labuta, à míngua de opções, sem remuneração pelos serviços, apenas em troca de casa e alimento, convertendo-se, com o passar do tempo, em agregados, sendo tratados (por vezes melifluamente) ora como serviçais, ora como familiares de segunda categoria, num limbo social e também jurídico, sem direito a herança, salário ou aposentadoria.

O trabalho doméstico é diferenciado do trabalho em geral pela finalidade não lucrativa no labor doméstico. Essa distinção era corroborada e marcada pela disparidade de direitos que assistiam aos empregados em geral, mas denegada aos empregados domésticos.

Essa distinção permanece até hoje, sendo o trabalho doméstico definido, primeiramente, já em 1941, pelo Decreto-Lei 3.078, que assim determina: "são empregados domésticos todos aqueles que, de qualquer profissão ou mister, mediante remuneração, prestam serviços em residências particulares ou em benefício destas".

A partir da primeira definição do trabalho doméstico, em 1941, aos domésticos foram garantidos alguns direitos. Sérgio Pinto Martins ensina sobre o tema: "Tinham os domésticos direito a aviso prévio de oito dias, depois de um período de prova de seis meses” (1999, p. 19).

Contudo, a Consolidação das Leis do Trabalho, ao ser adotada, em 1943, excluiu de sua proteção os trabalhadores domésticos, dispondo, expressamente, em seu artigo $7^{\circ}$ tal comando. Assim, foi consolidado e normatizado o desequilíbrio de direitos entre os domésticos e os demais trabalhadores.

Por outro lado, a Lei 5.859, de 1972, regulou e trouxe, de maneira tímida, alguns direitos para os empregados domésticos, concedendo-lhes três prerrogativas básicas: férias anuais, carteira de trabalho e benefícios da previdência social.

A condição mencionada acima representou a ruptura real com o pensamento que predominava na época de que os domésticos necessitavam apenas de comida e um lugar para morar, pois eram apenas os antigos escravos desqualificados que estavam recebendo um "auxílio" do tomador de serviço. Entretanto, a Lei 5.859 garantiu aos domésticos direitos mínimos, consubstanciando o desequilíbrio entre os trabalhadores.

A Constituição Federal de 1988, ao entrar em vigor, ampliou os direitos dos empregados domésticos, além dos já obtidos com a Lei 5.859/72: salário-mínimo, irredutibilidade do salário, décimo terceiro salário, repouso semanal remunerado, férias anuais remuneradas, licença à gestante, licença paternidade, aviso prévio proporcional e integração à Previdência Social.

Todavia, o próprio texto constitucional, lei máxima nacional, em seu artigo $7^{\circ}$, parágrafo único, traz de maneira expressa o desequilíbrio de direitos, ou seja, determina que aos domésticos não estão garantidos todos os direitos conferidos aos celetistas em geral. 
Evanna Soares fala sobre o tema:

Se essa desigualdade é inegável, como demonstrado, não corrigida nem pela Constituição de 1988 - conhecida como "Constituição Cidadã" - deve-se procurar a sua razão de ser na formação legislativa, econômica e política do Brasil, enfim, nas raízes e no pensamento constitucional brasileiro.

Buscando elucidar as razões de tamanha distinção, trazemos o ensinamento de Casagrande:

O escravagismo permeou as relações sociais brasileiras para além da questão racial, uma vez que aquele regime influiu também no modo como a sociedade brasileira valora o trabalho manual, em especial o prestado no âmbito doméstico por serviçais, do que é prova a situação de notória discriminação a que estão relegados, até hoje, os trabalhadores domésticos.

Ao longo dos anos, essa disparidade foi sendo mitigada gradativamente com a criação e ampliação de direitos para os empregados domésticos. Após a Lei 5.859 de 1972 e a CF de 1988, foi feita a Lei 10.208 em 2001, que deu direito aos recursos do Fundo de Garantia do Tempo de Serviço (FGTS), porém a sua inscrição foi facultativa.

A Lei 11.324 de 2006 trouxe como principal modificação a vedação de descontos nos salários dos domésticos de valores referentes à alimentação, vestuário, higiene e moradia.

A Emenda Constitucional 72 é o marco final dessa evolução de direitos, trazendo de vez a equiparação entre os celetistas em geral e os empregados domésticos. A ampliação de direitos trazidos pela EC 72, para muitos doutrinadores e estudiosos, foi até tardia, ao igualá-los, somente agora, aos demais empregados regidos pela CLT, ou seja, somente no século XXI foram rompidos os últimos elos de discriminação contra os empregados domésticos, que nos reportavam às suas raízes escravagistas.

\section{Os Novos Direitos dos EMPRegados Domésticos}

A equiparação em direitos está agora garantida na norma máxima do ordenamento jurídico Pátrio, mas na forma como foi concebida, está distante da realidade dos empregados domésticos brasileiros.

Há direitos com eficácia limitada, que deverão ser regulamentados pelas leis infraconstitucionais em até 90 (noventa) dias, alguns poucos, de eficácia plena, já devendo estar em prática.

A melhor compreensão da Emenda Constitucional necessita de dois conceitos criados por José Afonso da Silva. Assim, é essencial pormenorizar o que são normas de eficácia plena e normas de eficácia limitada.

José Afonso da Silva afirma que a doutrina moderna tende a considerar que todas as normas constitucionais, mesmo as de conteúdo subjetivo, teriam eficácia plena. Apesar dessa característica, alguns artigos da Carta Magna brasileira possuem eficácia limitada, mas o autor ressalta, entretanto, que a maioria dos dispositivos da Constituição Federal de 1988 comporta normas de eficácia plena e aplicabilidade direta e imediata. (2001, p. 89).

Assim, é de eficácia plena o texto que não requer qualquer tipo de norma ou ser regulamentando, sendo aplicado de imediato. Estabelece como deve ser feito, sem precisar de qualquer complementação e sem possibilitar que seja regulado de outra forma.

José Afonso da Silva ressalta que não há critérios únicos e seguros para distinguir as normas constitucionais de eficácia plena de outras, no entanto é possível estabelecer regras gerais sobre o assunto. Dentre elas, o autor destaca o critério da autoaplicabilidade. (SILVA, 2001, p. 99). 
Assim, José Afonso da Silva conclui:

Completa, nesse sentido, será a norma que contenha todos os elementos e requisitos para a sua incidência direta. Todas as normas regulam certos interesses em relação a determinada matéria. Não se trata de regular a matéria em si, mas de definir certas situações, comportamentos ou interesses vinculados a determinada matéria. Quando essa regulamentação normativa é tal que se pode saber, com precisão, qual a conduta positiva ou negativa a seguir, relativamente ao interesse descrito na norma, é possível afirmar-se que esta é completa e juridicamente dotada de plena eficácia, embora possa não ser socialmente eficaz. Isso se reconhece pela própria linguagem do texto, porque a norma de eficácia plena dispõe peremptoriamente sobre os interesses regulados. (2001, p. 99).

Dessa maneira, o autor define as normas de eficácia plena como as que podem ser aplicadas imediatamente, independentemente de posteriores normas infraconstitucionais que as detalhe, por já conterem em si todos os elementos necessários para a sua aplicação imediata. As normas de eficácia plena possuem todos os elementos e condições necessários à sua plena execução.

Segundo José Afonso da Silva, é difícil encontrar um termo apropriado para conceituar as normas de eficácia limitada. No entanto, apesar da imprecisão terminológica, mais importante que o uso de uma palavra determinada deve ser a explicitação do sentido que ela expressa. (2001, p. 118).

Assim, o autor escolheu a palavra "limitada" para designar esse tipo de norma constitucional que ele divide em dois grupos: normas constitucionais de princípio institutivo e normas constitucionais de princípio programático. (SILVA, 2001, p. 119).

As normas constitucionais de princípio institutivo ou organizativo contêm apenas o começo, o esquema geral de determinado órgão, entidade ou instituição. A efetiva criação, organização ou estruturação fica a cargo de normatização infraconstitucional na forma prevista pela Constituição.

As normas constitucionais de princípio programático são esquemas genéricos que destacam programas a serem desenvolvidos posteriormente pelo legislador infraconstitucional (SILVA, 2001, p. 137). Apesar da dificuldade de receberem precisão de conceito, José Afonso da Silva assim as define:

Podemos conceber como programáticas aquelas normas constitucionais através das quais o constituinte, em vez de regular, direta e imediatamente, determinados interesses, limitou-se a traçar-lhes os princípios para serem cumpridos pelos seus órgãos (legislativos, executivos, jurisdicionais e administrativos), como programas das respectivas atividades, visando à realização dos fins sociais do Estado. (2001, p. 138).

As normas constitucionais programáticas, apesar de terem eficácia limitada, impõem limites e restrições aos sujeitos a que elas se dirigem, e, portanto, exercem importante papel na ordem jurídica e no regime político do Brasil. (SILVA, 2001, p. 139).

Assim, as normas programáticas indicam para legislação infraconstitucional um caminho a seguir. Elas podem não obrigar o legislador a normatizar no sentido apontado por elas, mas pelo menos, com certeza elas obrigam que ele não legisle em sentido contrário.

Analisaremos, a seguir, de maneira pormenorizada, cada um dos novos direitos concedidos pela Emenda Constitucional 72 a fim de classificá-los em normas de eficácia limitada ou plena.

O seguro-desemprego é uma assistência financeira temporária garantida ao trabalhador demitido sem justa causa, que visa auxiliar o desempregado na sua subsistência, assim como na de seus familiares. 
Nesse sentido, Cassar leciona: “O direito ao seguro-desemprego só foi estendido ao doméstico cujo contrato for regido pelo fundo de garantia, e, mesmo assim, desde que estejam preenchidos os requisitos legais." (2011, p. 401).

Será concedido, exclusivamente, ao empregado doméstico inscrito no FGTS por um período mínimo de quinze meses nos últimos 24 meses, contados da dispensa sem justa causa. Faz-se necessário a observação de que, antes da Emenda Constitucional, o empregador escolhia se incluía ou não o seu empregado doméstico no Fundo de Garantia do Tempo de Serviço (FGTS), pois era mera faculdade do tomador de serviço. Diante disso, a grande maioria dos empregados domésticos não tinha direito ao respectivo benefício.

O benefício do seguro-desemprego aos domésticos que preenchessem os requisitos consistia no pagamento no valor de um salário-mínimo, por um período máximo de três meses, de forma contínua ou alternada.

Após a Emenda, fica o questionamento de como o referido direito será regulamentado. A regra antiga, exposta acima, determinava que o valor era sempre de um salário-mínimo por no máximo três meses. Porém, a equiparação em direitos trazida pela EC 72 faz os domésticos buscarem a aplicação do seguro na mesma forma dos demais celetistas, com base na Lei 7.998 de 1990, a qual prevê até cinco parcelas com o valor do benefício superior ao salário-mínimo, dependendo da remuneração que era percebida.

A nova Emenda traz o seguro-desemprego de maneira obrigatória ao determinar que o tomador de trabalho inscreva o empregado doméstico no regime do FTGS. A medida possibilitará a grande maioria dos trabalhadores domésticos gozar do referido benefício caso necessitem, haja vista que, quando era uma faculdade do empregador, a grande maioria dos patrões não optava pelo regime do FGTS, visando diminuir os custos da contratação.

A indenização em demissão sem justa causa segue em determinadas proporções o posicionamento já exposto aqui sobre o seguro-desemprego.

Explicando melhor, a indenização em demissão sem justa causa é disciplinada pelo artigo 478 da CLT, porém, a Carta Magna promulgada em 1988 definiu que o único regime de proteção aos empregados passou a ser o Fundo de Garantia do Tempo de Serviço. Assim, após 1988, os empregados que não tinham direito adquirido passaram a ser indenizados da seguinte forma: $40 \%$ sobre o saldo do FGTS constante na época da terminação do contrato.

Como já mencionado, a inscrição do empregado doméstico no regime do FGTS era mera faculdade do empregador, conforme disposição do artigo 3-A da Lei 5.859 de 1972.

Convém o ensinamento de Cassar sobre o assunto:

$\mathrm{O}$ art. $7^{\circ}$, I, da CRFB, determinou, nos termos da lei complementar, o pagamento de indenização compensatória devida ao empregado em caso de despedida arbitrária. Esta indenização compensatória deve ser considerada, até que seja promulgada a lei complementar, ao percentual incidente sobre o FGTS nos casos de despedida arbitrária ou nos demais casos legais. (2011, p. 1254).

Assim, depreende-se que se era faculdade do empregador inscrever ou não o seu empregado no FGTS, não era, pois, obrigatório o pagamento da indenização de $40 \%$ sobre o valor do FGTS. Assim, a obrigatoriedade da inscrição dos domésticos no FGTS, trazida pela EC 72, torna obrigatório, consequentemente, o pagamento da indenização em casos de demissão sem justa causa.

Após a obrigatoriedade trazida para o pagamento da indenização em casos de demissão sem justa causa, o questionamento que surge é de qual será o percentual da indenização 
no caso dos domésticos. A matéria é pendente de norma regulamentadora, entretanto, empregados e tomadores de serviço divergem sobre o valor do percentual.

Os tomadores de serviço, utilizando aquela distinção trazida no início do presente estudo, argumentam que por não possuírem finalidade de lucro e serem pessoas físicas não detêm o mesmo poderio econômico de uma empresa. Diante disso, a manutenção de um percentual de $40 \%$ será por demais gravoso para os empregadores, extrapolando a capacidade financeira dos tomadores de serviço.

Do outro lado, os empregados domésticos argumentam que a redução da porcentagem da multa será um retrocesso diante dos avanços trazidos pela EC 72.

O Ministro do Trabalho, Manoel Dias, se manifestou sobre o tema: "Nós estamos propondo a multa de 40\%, [ou seja], estendendo aos trabalhadores domésticos os direitos das outras categorias". O embate sobre o assunto persiste, sendo um dos temas a serem regulamentados que gera maior expectativa de ambos os lados.

O salário-família é o benefício pago aos segurados mensalmente, hoje de até R \$971,78, para auxiliar no sustento dos filhos de até 14 anos de idade ou inválidos de qualquer idade.

A concessão do salário-família não exige tempo mínimo de contribuição; esse benefício atualmente fica a cargo da Previdência Social. A ampliação desse direito aos domésticos, todavia, está gerando grande preocupação.

A Previdência Social está em um processo de crescente acúmulo de dívidas, ou seja, suas receitas não são suficientes para o pagamento de todos os beneficiários que estão em gozo de algum tipo de benefício. O salário-família, na forma atual, é encargo exclusivo da Previdência Social. Assim, a ampliação desse benefício aos domésticos aumentará ainda mais o déficit previdenciário.

No tocante à sua regulamentação, o maior dilema é qual será a origem das verbas para o pagamento do salário-família.

O adicional noturno também foi estendido aos domésticos. A jornada de trabalho considerada noturna é a que acontece entre as $22 \mathrm{~h}$ de um dia até às $5 \mathrm{~h}$ do dia seguinte. Assim, o doméstico que exercer sua atividade após as $22 \mathrm{~h}$ deverá receber um adicional noturno. A Consolidação das Leis do Trabalho no caput do artigo 76 determina que o acréscimo no salário deve ser de $20 \%$. Entretanto, novamente mencionamos que os domésticos não estão cobertos pelas regras da CLT.

O direito constitucional ampliado aos empregados domésticos determina apenas que a remuneração do trabalho noturno deve ser superior à do diurno. O percentual da majoração ficou pendente de regulamentação.

Os empregados domésticos lutam aqui, novamente, pela aplicação do benefício na forma trazida pela CLT. Os empregadores, do outro lado, afirmam que por não serem aplicadas as regras celetistas aos domésticos o percentual de acréscimo deve ser menor, a fim de reduzir os enormes gastos acarretados pelos novos direitos.

Outra indignação pertinente ao tema é a redução da hora de trabalho noturno de 60 minutos para 52’30”.

A redução está também contida na CLT, artigo 76, parágrafo 1. Os tomadores de serviço de antemão já afirmam que a redução não é estendida aos domésticos. Os laborantes, em posição contrária, defendem que a redução da duração da hora noturna decorre do comando constitucional da remuneração superior do trabalho noturno. O tema, todavia, somente será elidido com a manifestação do legislador infraconstitucional. 
O auxílio-creche é o valor que o empregador repassa diretamente às empregadas, de forma a não ser obrigado a manter uma creche. No caso das empregas domésticas, o benefício deve ser concedido a toda empregada mãe.

Os doutrinadores do tema em suas primeiras manifestações, após a Emenda 72, defendem que o valor do benefício deve ser objeto de negociação coletiva entre os sindicatos patronais e laborais.

A solução apresentada pela doutrina parece acertada, porém, há um entrave na realidade brasileira. Antes da EC 72, somente onze estados da federação possuíam sindicatos laborais. Já os sindicatos patronais existiam em apenas quatro estados.

A efetivação do direito, diante do quadro apresentado, deverá ser feita pela fixação de um valor pelo legislador infraconstitucional. A fixação de modo arbitrário, como deve ocorrer, fatalmente prejudicará uma das partes. Vejamos a razão.

O Brasil é um país imenso, portanto, possui acentuada diferença de padrão econômico de um Estado para outro. Assim, a fixação de um auxílio-creche baixo não prejudicará os empregadores de nenhum estado. Contudo, nos estados de padrão econômico mais elevado ficará praticamente sem efeito para os trabalhadores domésticos.

Ao contrário, a fixação de um valor elevado de auxílio-creche atenderá às necessidades dos empregados domésticos de todo o país. Porém, os empregadores de estados com um menor poderio econômico serão agravados em demasia. Assim, a melhor solução, realmente, seria a negociação coletiva do valor do auxílio, mas essa alternativa ainda está distante da realidade brasileira.

O seguro contra acidente de trabalho é um direito do trabalhador previsto na Constituição, sendo de responsabilidade do empregador o seu recolhimento mediante pagamento de um adicional sobre a folha de salários de seus empregados, com alíquotas que podem variar entre $1 \%$ a $3 \%$, conforme o grau de risco da atividade.

Aqui, novamente, surgem questionamentos. A atividade desempenhada pelos domésticos é desenvolvida no ambiente residencial, com o intuito de auxiliar os tomadores de serviço na manutenção de suas residências e cuidados com a família. Assim, é questionada a existência de risco em tais atividades.

Outro questionamento é o tocante aos empregados que residem com o patrão. Segundo a Lei 6.367 de 1976, parágrafo 2º o empregado será considerado em serviço: "Nos períodos destinados a refeição ou descanso, ou por ocasião da satisfação de outras necessidades fisiológicas, no local do trabalho ou durante este, o empregado será considerado a serviço da empresa".

Assim, o empregado que mora na mesma residência do patrão estará durante os seus períodos de descanso em seu ambiente de trabalho. Um acidente que ocorra nesse intervalo, será um acidente de trabalho? A Lei 6.367 aponta que sim, porém, tal entendimento tornaria o empregado doméstico que reside no mesmo local em que o patrão, está a todo momento em serviço, posicionamento até desarrazoado.

Além disso, novamente é suscitada pelos empregadores a equiparação de obrigações entre o empregador doméstico e uma empresa. A alíquota do seguro seria a mesma para empresas e tomadores de serviços domésticos, variando apenas conforme atividade. Essa equiparação é desproporcional, segundo os empregadores domésticos, pois os estes não possuem de maneira alguma o mesmo poderio econômico de uma empresa.

A Emenda, entretanto, torna obrigatórios os depósitos mensais do valor de contribuição referente ao seguro de acidente de trabalho, estando ainda aguardando regulamentação. 
A limitação da jornada de trabalho não contemplava os empregados domésticos. Assim, não possuíam, anteriormente, nenhuma limitação de jornada laboral.

A limitação da jornada de trabalho em até 44 (quarenta e quatro) horas semanais está contida na CLT no capítulo II, da duração do trabalho. Como aos domésticos não se aplicam as regras previstas na CLT, são excluídos, pois, desse capítulo e das limitações por ele trazidas.

O limite à jornada laboral para o doméstico foi trazido somente pela Emenda Constitucional 72. A norma é de eficácia plena, possuindo, portanto, aplicação imediata.

O pagamento de horas extras passa necessariamente pela limitação da jornada de trabalho. Assim, os empregados domésticos, como não tinham limites para suas jornadas de labor, não eram passíveis da percepção de tal direito.

Agora, após a EC 72, que trouxe a limitação da jornada laboral, é possível o recebimento de valor por jornada extraordinária.

Sobre horas extras, Sérgio Pinto Martins ensina:

Horas extras são as prestadas além do horário contratual, legal ou normativo, que devem ser remuneradas com o adicional respectivo. A hora extra pode ser realizada tanto antes do início do expediente, como após seu término normal ou durante os intervalos destinados a repouso e alimentação. (2012, p. 533).

A jornada extraordinária deverá ser remunerada com o acréscimo de no mínimo $50 \%$ da hora normal, segundo o inciso XVI da CF de 1988. Assim, as horas extras dos domésticos são de eficácia plena.

O reconhecimento de acordos e convenções coletivas é antigo no Direito do Trabalho, uma vez que decorre do Princípio da Normatização Coletiva, considerado uma das diretrizes do Direito do Trabalho.

O princípio está positivado na CLT, artigo 611, porém esse era antes excluído dos empregados domésticos, situação agora alterada pela Emenda Constitucional, não pela extensão das regras da CLT aos domésticos, mas pela EC 72.

Leciona Cassar sobre o tema que: "Suas cláusulas são comandos abstratos, gerais e impessoais. Em face disto, a convenção ou o acordo coletivo se assemelham à lei.” (2011, p. 1326).

O reconhecimento de acordos e convenções coletivas é mais um direito de aplicação imediata, ou seja, norma de eficácia plena.

Em suma, os novos direitos de eficácia plena são a jornada de trabalho definida em oito horas diárias ou 44 horas semanais, recebimento de horas extras, caso existam, e o reconhecimento de convenções ou acordos coletivos.

Os direitos de eficácia limitada são seguro-desemprego, indenização em demissões sem justa causa, salário-família, adicional noturno, auxílio-creche e seguro contra acidente de trabalho.

\section{Resultados}

A dita EC 72 causou enorme repercussão na sociedade desde quando era ainda apenas um Projeto de Emenda. Uma das razões de tamanha manifestação é o grande número de indivíduos atingidos diretamente por essa Emenda (segundo dados do IBGE, no Brasil, são cerca de sete milhões de empregados domésticos).

Um dos temas de maior discussão é o controle da jornada de trabalho. A Consolidação das Leis do Trabalho, no artigo 74, parágrafo $2^{\circ}$, traz a obrigatoriedade de registro escrito da 
jornada apenas para empresas com mais de dez empregados, regra não aplicada aos domésticos tanto por ser da CLT, quanto por a situação, se aplicável, fugir da realidade da quase totalidade dos empregados.

O controle da jornada está sendo muito repercutido por parte dos empregadores na busca de tentar exigir o efetivo cumprimento das 44 horas agora estabelecidas. Além disso, o registro formal da jornada laboral está sendo utilizado por alguns como medida preventiva, a fim de se resguardarem para evitar possíveis ações judiciais trabalhistas, cobrando horas extras, agora possíveis.

Pelo prisma dos empregados, o registro da jornada de trabalho, embora não obrigatório, também é benéfico, pois evitará que a jornada laboral se estenda para além das 44 horas trazidas pela EC 72. Caso ultrapasse o limite determinado, sendo a jornada registrada, ficará mais fácil a comprovação das horas excedentes, que devem ser pagas com acréscimo de $50 \%$, deixando, assim, o empregado mais protegido.

O site da República Federativa do Brasil traz uma orientação sobre a temática acima:

Com a carga horária de oito horas diárias ou 44 semanais, o controle deverá ser feito de forma manual, como admite a Consolidação das Leis do Trabalho, em livro de ponto ou quadro de horário onde a trabalhadora doméstica irá assinar diariamente o horário de entrada e saída do trabalho.

Como já abordado anteriormente, de maneira até exaustiva, um grande número de direitos trazidos pela Emenda 72 são de eficácia limitada, ou seja, estão pendentes de regulamentação para ter aplicabilidade. Aproveitando-se disso, alguns empregadores, para evitar os novos custos acarretados pela EC 72 com o empregado doméstico, estão utilizando esse período anterior à regulamentação dos direitos para demitirem seus empregados domésticos.

As notícias que estão sendo veiculadas na mídia comprovam essa atitude de alguns tomadores de serviço. A reportagem da Band News de Curitiba mostra isso: "O número de demissões de empregadas domésticas cresceu 30\% em Curitiba desde a aprovação da emenda constitucional número 72" (Online).

O Portal do Consumidor, em entrevista com o advogado do Sindicato dos Trabalhadores Domésticos do Município de Niterói e Regiões, Gilmar de Almeida, confirma essa prática: "Da reta final da aprovação da PEC, em março, até agora, as dispensas aumentaram em $50 \%$ no sindicato".

A capa do jornal Diário de Pernambuco de 10 de abril demonstra de maneira clara essa medida: "O sindicato das domésticas e o patronal confirmam que, na primeira semana da vigência da nova legislação, os desligamentos formais de empregadas cresceram $60 \%$ na RMR".

\section{Considerações Finais}

A ampliação de direitos foi a ruptura final de um desequilíbrio de direitos normatizado. Assim, a promulgação da Emenda Constitucional 72 equiparou perante a legislação os trabalhadores, sendo, para muitos, uma medida até tardia diante do quadro democrático institucionalizado no Brasil desde a Carta Magna de 1988.

As dúvidas, entretanto, nasceram junto com a nova norma constitucional, pois os direitos de eficácia limitada, ou seja, os que necessitam de legislação infraconstitucional para trazê-los à realidade fática dos domésticos, ainda não foram definidos. O prazo para a regulamentação desses direitos é de noventa dias. 
É inegável, diante de tudo exposto, que os novos direitos dos empregados domésticos trarão ônus aos empregadores, principalmente porque antes da Emenda a grande maioria dos empregadores não tinham seus empregados inscritos no regime do FGTS.

Assim, enquanto muitos direitos não possuem aplicabilidade por não estarem regulados, os empregadores estão optando pela demissão dos seus domésticos. Essa prática, entretanto, deve cessar com a regulamentação de todos os direitos, pois com todos os novos direitos em prática uma demissão injustificada de um doméstico ficará muito onerosa, principalmente sendo mantido o percentual de multa em $40 \%$.

\section{REFERÊNCIAS}

ANDRADE, Dárcio Guimarães. Empregado Doméstico. Rev. TRT - $3^{\mathrm{a}}$ R. - Belo Horizonte, 27(57):69-75, Jul. 97/Dez. 97.

BARROSO, Felipe dos Reis. Manual de Formatação de Monografia Jurídica. 2. ed. Fortaleza: Book, 2012.

BRASIL. Constituição (1998). Constituição da República Federativa do Brasil. Brasília: DF, Senado, 1998.

BRASIL. Consolidação das Leis do Trabalho. Decreto-Lei no 5452, de $1^{\circ}$ de maio de 1943. Aprova a consolidação das leis do trabalho. Lex: Coletânea de Legislação: edição federal. São Paulo, v. 7, 1943. Suplemento.

CASAGRANDE, Cássio. Trabalho doméstico e discriminação. Boletim CEDES [on-line], Rio de Janeiro, setembro de 2008, pp. 21-26. Disponível em: <http://www.cedes.iuperj.br $>$. Acesso em: 16 maio 2013.

CASSAR, Vólia Bomfim. Direito do Trabalho. 5. ed. Niterói: Impetus, 2011.

CAVALCANTI, Ricardo Russell Brandão. "Da eficácia das normas constitucionais". In: Âmbito Jurídico, Rio Grande, XIV, no 86, mar 2011. Disponível em: < $\underline{\text { http://www.ambitojuridico.com.br/ }}$ site/index.php?n_link=revista_artigos_leitura\&artigo_id=9194>. Acesso em: 16 maio 2013.

ECO, Umberto. Como se faz uma tese. 12. ed. São Paulo: Perspectiva, 1995.

MARTINS, Sérgio Pinto. Manual do Trabalho Doméstico. 4. ed. São Paulo: Atlas, 1999.

Direito do Trabalho. 28. ed. São Paulo: Atlas, 2012.

SILVA, José Afonso da. Aplicabilidade das Normas Constitucionais. 5. ed. São Paulo: Malheiros, 2001.

SOARES, Evanna. "Abolição da escravatura e princípio da igualdade no pensamento constitucional brasileiro. Reflexos na legislação do trabalho doméstico". Jus Navigandi, Teresina, ano 16, no 2835, 6 abr. 2011. Disponível em: <http://jus.com.br/revista/texto/18842>. Acesso em: 16 maio 2013.

$<$ http://bandnewsfmcuritiba.com/2013/04/25/apos-pec-das-dometicas-aumenta-30-o-numero-de-demissoes-em-curitiba/> Acesso em: 16 maio 2013.

$<\underline{\text { http://blogs.diariodepernambuco.com.br/diretodaredacao/2013/04/10/capa-do-dia-10042013/> }}$ Acesso em: 17 maio 2013. 
$<$ http://congressoemfoco.uol.com.br/noticias/governo-quer-multa-de-40-para-demissao-de-domesticas/>. Acesso em: 12 maio 2013.

$<$ http://www.brasil.gov.br/noticias/arquivos/2013/04/03/nova-lei-do-trabalho-domestico-comeca-a-valer-a-partir-desta-quarta-feira-3>. Acesso em: 15 maio 2013.

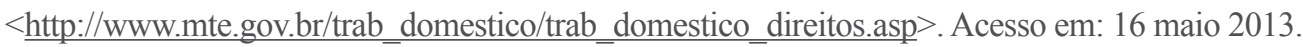

$<$ http://www.portaldoconsumidor.gov.br/noticia.asp?busca $=$ sim\&id $=23805>$. Acesso em: 16 maio 2013.

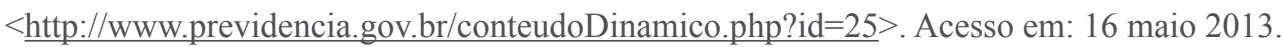

\section{CONSTITUTIONAL AMENDMENT $N^{\circ}$ 72/2013 AND NEWLABOUR RIGHTS FOR DOMESTIC WORKERS}

Abstract: In Brazil, the Constitutional Amendment n. 72/2013 (EC 72) extended to domestic workers various labour rights. The new dispositions added to the Constitution represent a huge breakthrough for all domestic workers, as equalized their rights to employees under the Consolidation of Labor Laws (CLT). This article exposes some consequences already observed after the publication of the said amendment.

Keywords: Advertising. Constitutional Amendment 72. Domestic workers. New rights.

Data de recebimento: jun/2013 - Data de aprovação: jul/2013 